\title{
Overcrowding and exposure to secondhand smoke increase risk for COVID-19 infection among Latinx families in the greater San Francisco Bay Area
}

\author{
Andrea DeCastro Mendez ${ }^{1,2 *}$, Milagro Escobar ${ }^{1,2 *}$, Maria Romero ${ }^{1,2}$, Janet M. Wojcicki1,2
}

\begin{abstract}
INTRODUCTION Environmental risk factors, including community level pollution burden and exposure to smoking and secondhand smoke, have not been evaluated in relation to risk for infection with COVID-19 in high risk, urban Latinx families. METHODS We evaluated risk factors for COVID-19 infection in three, preexisting, longitudinal, Latinx family cohorts in the San Francisco Bay Area from May through September 2020 ( $N=383$ households, 1875 people). All households were previously recruited before the pandemic. For the COVID-19 sub-study, participants responded to a telephone interview where we assessed food consumption patterns, housing and employment status, and history of COVID-19 infection. Secondhand smoke exposure was based on previously collected selfreported data, and environmental pollution exposure was determined from census tract residence. Non-parametric tests and multiple logistic regression were used to assess independent predictors of COVID-19 infection.

RESULTS Larger household size increased risk for infection ( $\mathrm{OR}=1.58 ; 95 \%$ CI: $1.12-2.23, \mathrm{p}<0.01)$ as did increasing number of children in household ( $\mathrm{OR}=3.79$; 95\% CI: 1.51-9.56). Any exposure to secondhand smoke was also associated with increased risk for COVID infection (OR 4.69; 95\% CI: 1.01-21.85) and having a greater number of family members eating at home was protective against infection $(\mathrm{OR}=0.10 ; 95 \%$ CI: 0.02-0.52, $\mathrm{p}<0.01)$.

CONCLUSIONS Crowding, as indicated by larger household size, increases risk for COVID-19 infection in Latinx families, as does exposure to secondhand smoke. Public policy and health interventions need to ensure that multiunit residential complexes do not allow exposure to secondhand smoke between units, that individuals eat in the home environment, and that large households can safely separate individuals exposed to COVID-19.
\end{abstract}

\author{
AFFILIATION \\ 1 Department of Pediatrics, \\ Division of Pediatric \\ Gastroenterology, Hepatology \\ and Nutrition, University of \\ California, San Francisco, San \\ Francisco, United States \\ 2 Department of \\ Epidemiology and \\ Biostatistics, University of \\ California, San Francisco, San \\ Francisco, United States \\ ${ }^{*}$ Contributed equally \\ CORRESPONDENCE TO \\ Janet M. Wojcicki. \\ Department of Pediatrics, \\ Division of Pediatric \\ Gastroenterology, Hepatology \\ and Nutrition, University of \\ California, San Francisco, \\ 16th Street, 4th Floor, San \\ Francisco, CA 94134-0136, \\ United States. E-mail: Janet. \\ wojcicki@ucsf.edu
}

KEYWORDS

secondhand smoke, COVID-19, Latinx, nutrition

Received: 30 January 2021 Revised: 8 June 2021

Accepted: 4 August 2021

\section{INTRODUCTION}

The novel coronavirus (COVID-19) has infected over 33 million individuals in the US and approximately 589547 have died as of 26 May $2021^{1}$ (Centers for Disease Control and Prevention, 2021). COVID-19 disease disproportionately affects US racial and ethnic minorities ${ }^{2,3}$. The Latinx community constitutes $18 \%$ of the US population, but $28.8 \%$ of the confirmed COVID-19 cases. Pediatric COVID-19 infection rates are also higher in US racial and ethnic minorities. As of May 2021, there were approximately 3 million reported pediatric cases of COVID-194. In California as of June 2021, Latinx children accounted for $47.9 \%$ of the state's children, yet represented $65.4 \%$ of all child COVID-19 cases and $43.5 \%$ of deaths ${ }^{5}$. Similarly, in a study of pediatric COVID-19 cases from 15 states including District of Columbia (but not including California), Hispanic children had a rate of COVID-19 
that was 1.52 times higher than White children during $2020^{6}$.

In part, the increased risk for COVID-19 in Latinx families is due to environmental and living conditions. Latinx adults constitute a large proportion of the country's workforce but hold mostly low-paying positions that lack benefits such as health insurance ${ }^{7}$. When COVID-19 shelter-in-place began, 16.2\% of Latinx workers had the option to work from home in comparison with $29.9 \%$ of White workers ${ }^{8}$. Household vulnerability increases risk for COVID-19 infection based on factors such as crowding and multi-generational households ${ }^{9}$. California Latinx households are more likely to reside in homes with non-family members compared with non-Latinx households ${ }^{10}$.

Furthermore, extended exposure to air pollution, including secondhand smoke, can increase infection risk and mortality from COVID-19 by compromising respiratory health and increasing the risk for chronic cough $^{11-14}$. Minority communities, including Latinx families, are more likely to be residing in areas of high pollution density than their White counterparts ${ }^{15}$.

Shelter-in-place orders have also adversely impacted global nutritional health as individuals are more likely to have poorer-quality diets with more unhealthy eating practices $^{16,17}$. Poor nutrition, including low levels of vitamin D and selenium, can increase susceptibility to respiratory illness including potentially COVID-19 ${ }^{18,19}$. Western nutrition consisting of foods high in saturated fats, sugars and refined carbohydrates that activate the innate immune system while deactivating the adaptive immune system, can result in increased inflammation and diminished defence against viruses ${ }^{20}$. Dietary supplements and good nutrition can also be protective against pollution damage and beneficial in the context of airway disease $\mathrm{e}^{21}$.

In our COVID-19 risk study, we sought to assess the relationship between environmental risk factors including secondhand smoke exposure, environmental pollution and nutritional health, and COVID-19 infection in an urban, inner-city Latinx population. We also assessed the possible interactive relationship between pollution and nutrition and risk for COVID-19 infection in a high-risk population. Exposure to secondhand smoke and nutritional status are both modifiable risk factors and as such could potentially be important areas for prevention intervention.

\section{METHODS}

\section{Recruitment}

Families in the present study are part of three, longitudinal cohort studies of Latinx families: the Hispanic Eating and Nutrition Study (HEN) (original $\mathrm{N}=201)^{22,23}$, the Latinx, Eating, and Diabetes Study (LEAD) (original $\mathrm{N}=97)^{24,25}$, and the Telomeres at Birth Study (TAB) (original N=424). HEN and LEAD mothers were recruited during pregnancy primarily at Zuckerberg San Francisco General Hospital (ZSFG) with a minority from UCSF Benioff, whereas TAB participants were recruited in the postpartum unit before hospital discharge (mostly at UCSF Benioff and the remaining at ZSFG). Participants for these three studies have been followed over the course of 13,8 , and 1-2 years, respectively. Specifics of the studies have previously been described ${ }^{22-25}$.

We contacted participants in HEN, LEAD, and TAB by telephone from May through September 2020 to take part in this COVID-19 sub-study. Participants gave their language preference (Spanish or English) and were given information about the COVID-19 study by the bilingual research coordinators (ADM, $\mathrm{ME}$ and MR) and the principal investigator (JW). Those who chose to participate gave verbal consent for the 15-minute interview. We assessed COVID-19 symptoms and laboratory-based testing, food consumption patterns during COVID-19, and current employment and housing status. Participants received a $\$ 15$ gift card to Amazon or Target as compensation for study participation. The Committee on Human Research (CHR) of the UCSF Institutional Review Board approved all aspects of the study.

We used the CalEnviroScreen 3.0 (California Office of Environmental Health Hazard Assessment, 2018) to assess levels of pollution by census tract in the state of California ${ }^{26}$. Specifically, the CalEnviroScreen 3.0 determines California communities disproportionately affected by pollution by providing a pollution burden score and percentile.

\section{Procedures}

All participants were asked if they had symptoms consistent with COVID-19 from the start of lockdowns in March 2020 until the time of the interview (MaySeptember 2020). COVID-19 symptoms that we asked about included cough, fever, muscle aches, stomach ache, diarrhea, vomiting, sore throat, shortness of 
breath, COVID toes, or loss of smell or taste.

All participants were asked if someone in their household had undergone a COVID-19 test at a doctor's office, hospital, or testing site. Households were determined to be positive for COVID-19 if anyone reported a positive polymerase chain reaction (PCR test), and/or symptoms including loss of taste/ smell. The unit of analysis was at the level of the household with household deemed to be positive if anyone in the household reported a COVID-19 positive test result. Other questions focused on household crowding including household size, number of bedrooms and bathrooms, and number of household members sharing bedrooms and bathrooms. We also assessed the number of working days each week for household members, frequency of eating together at home, and COVID-19 specific risk factors including the use of face masks in public and the frequency of public transportation use.

At the baseline assessment of all families for initial cohort enrollment, we collected maternal primary language use (English, Spanish, or bilingual) and education level (primary or less than a high school diploma, high school diploma, some college or more). We also annually collected information on exposure to secondhand smoke in the household. We were able to use the address of residence at the time of the COVID-19 sub-study to find the CalEnviroScreen3.0 score for each participant to identify the extent to which participants were impacted by pollution including PM2.5 exposure, pesticide use, diesel particulate matter, and drinking water contamination ${ }^{26}$.

\section{Statistical analysis}

We combined HEN and LEAD cohorts for a total of 183 families for analysis as recruitment specifics and demographics of these cohorts are similar (both recruited at ZSFG primarily with similar exclusion and inclusion criteria $)^{23-25}$. The TAB cohort was analyzed separately and only participants who identified as Latinx were included in the analysis ( $n=200$ families). Data were assessed for normality using graphical tests of normality and statistical tests including the ShapiroWilk and the Kolmogorov-Smirnov tests. As the data were not normally distributed, we used non-parametric tests of association including the Wilcoxon rank sum test and the chi-squared test to assess measures of association for continuous and categorical data.

Variables that were significant in bivariate analysis at $\mathrm{p}<0.20$ were included in multivariable analyses. We set a higher threshold than $\mathrm{p}<0.05$ to include variables in multivariable models to prevent any type II errors, or accepting the null hypothesis when there is actually an association. Other variables that have been shown to be associated with COVID-19 infection based on biological plausibility were also included in models even if they did not meet the statistical threshold, such as secondhand smoke exposure due to possible associations with other respiratory illnesses. We ran separate analyses for the HEN/LEAD versus the TAB cohorts. We conducted secondary multivariable analyses for both HEN/ LEAD and TAB that assessed possible interactions between dietary factors and exposure to secondhand smoke in relation to COVID-19 infection. Statistical significance for findings was set at $p<0.05$. All analyses were conducted using Stata 15.1 (StataCorp LP).

\section{RESULTS}

Of the 183 families in the combined HEN/LEAD cohorts, there were 14 families with cases $(7.6 \%)$ of COVID-19 reported (Table 1). The TAB cohort had 200 families and 7 cases of COVID-19 (3.5\%) (Table $2)$.

\section{Sociodemographics}

Larger household size was associated with COVID-19 infection in HEN/LEAD cohorts $(6.2 \pm 2.7$ vs $4.9 \pm 1.6$, $\mathrm{p}=0.02$; Table 1 ). More family members sharing bedrooms were also associated with increased risk for infection $(2.9 \pm 1.5$ vs $2.5 \pm 1.2, \mathrm{p}=0.03$; Table $1)$. Increasing number of people eating together approached statistical significance for COVID-19 infection but did not reach significance $(p=0.07$; Table $1)$. For the TAB cohort, a higher number of children in the household was associated with increased risk for infection $(3.3 \pm 1.3$ vs $2.4 \pm 1.1, \mathrm{p}=0.03$; Table 2$)$. A greater number of individuals eating together was protective against infection $(2.7 \pm 0.8$ vs $3.8 \pm 1.2$, $\mathrm{p}=0.01$; Table 2). We did not find any association between COVID-19 infection and maternal high school diploma, primarily Spanish language use or Mexican origin (vs Central American or other Hispanic ethnicity) for HEN/LEAD or the TAB cohorts. 
Table 1. Family demographics, diet and COVID-19 infection of HEN and LEAD combined cohorts in the San Francisco Bay Area (Total=183)

\begin{tabular}{|c|c|c|c|c|c|}
\hline & \multicolumn{2}{|c|}{$\begin{array}{c}\text { Infected } \\
\mathrm{N}=14(7.6 \%)\end{array}$} & \multicolumn{2}{|c|}{$\begin{array}{c}\text { Not Infected } \\
\mathbf{N}=169(92.4 \%)\end{array}$} & \multirow[t]{2}{*}{$p$} \\
\hline & Mean $\pm \mathrm{SD}$ & Median (IQR) & Mean \pm SD & Median (IQR) & \\
\hline \multicolumn{6}{|l|}{ Demographics } \\
\hline Household size & $6.2 \pm 2.7$ & $5.0(1.0)$ & $4.9 \pm 1.6$ & $5.0(2.0)$ & 0.02 \\
\hline Number of children & $3.9 \pm 1.1$ & $3.0(2.0)$ & $2.8 \pm 1.2$ & $3.0(1.0)$ & 0.47 \\
\hline Number sharing bedroom & $2.9 \pm 1.5$ & $2.3(2.0)$ & $2.5 \pm 1.2$ & $2.0(1.0)$ & 0.03 \\
\hline Number sharing bathroom & $4.8 \pm 1.3$ & $5.0(1.0)$ & $4.0 \pm 1.7$ & $4.0(2.0)$ & 0.40 \\
\hline Number eating together & $4.6 \pm 1.8$ & $5.0(2.0)$ & $4.1 \pm 1.4$ & $4.0(2.0)$ & 0.07 \\
\hline Maternal high school diploma, n (\%) & $7(50)$ & \multicolumn{3}{|c|}{$95(57.9)$} & 0.57 \\
\hline Spanish language (primary), n (\%) & $13(92.9)$ & \multicolumn{3}{|c|}{$154(91.7)$} & 0.88 \\
\hline Mexican origin, $\mathrm{n}(\%)$ & $8(57.1)$ & \multicolumn{3}{|c|}{$95(56.2)$} & 0.95 \\
\hline \multicolumn{6}{|l|}{ COVID practices } \\
\hline Wearing masks (always), n (\%) & $13 / 13(100)$ & & 154/162 (95.1) & & 0.41 \\
\hline Using public transportation (never), n (\%) & $12 / 13(92.3)$ & & $127 / 162(78.4)$ & & 0.23 \\
\hline Household member working/employed, n (\%) & $9 / 13(69.2)$ & & $93 / 156(59.6)$ & & 0.50 \\
\hline \multicolumn{6}{|l|}{ Diet } \\
\hline Fast food ( $\geq 2$ times/month), $\mathrm{n} / \mathrm{N}(\%)$ & $8 / 12(66.7)$ & & $59 / 149(39.6)$ & & 0.07 \\
\hline Mexican tortas ( $\geq 2$ times/month), n/N (\%) & $3 / 12(25)$ & & $16 / 147(10.9)$ & & 0.15 \\
\hline Sugar sweetened beverages ( $\geq 1$ time/week), n/N (\%) & $6 / 12(50)$ & & $82 / 148(55.4)$ & & 0.71 \\
\hline Beans/frijoles ( $\geq 1$ time/week), n/N (\%) & $11 / 12$ (91.7) & & $104 / 147$ (70.8) & & 0.12 \\
\hline $100 \%$ Fruit juice ( $\geq 1$ time/week), n/N (\%) & $7 / 12(58.3)$ & & $87 / 147(59.2)$ & & 0.95 \\
\hline \multicolumn{6}{|l|}{ Pollution } \\
\hline $\begin{array}{l}\text { Exposure to secondhand smoke or someone smoking in } \\
\text { household, } \mathrm{n} / \mathrm{N}(\%)\end{array}$ & $4 / 14(28.6)$ & & $30 / 165$ (18.2) & & 0.34 \\
\hline EnviroScreen 3.0 Pollution burden score & $4.4 \pm 0.9$ & $34.6(9.4)$ & $4.7 \pm 1.2$ & $38.6(14.2)$ & 0.32 \\
\hline EnviroScreen 3.0 Pollution burden percentile & $35.3 \pm 18.2$ & $30.9(23.9)$ & $42.1 \pm 23.6$ & $41.6(37.7)$ & 0.31 \\
\hline
\end{tabular}

\section{COVID-19 prevention and risk associated practices}

We did not find statistically significant differences between COVID-19 prevention practices, such as wearing masks and risk for infection (Tables 1 and 2 ). Both cohorts reported near universal mask use. There was also no association between COVID-19 and frequency of practices associated with elevated risk such as public transportation use. Having household members working outside of the house trended towards statistical significance in the TAB cohort with a higher percentage of families with a household member infected working outside the home (100\% vs $75.1 \%$, $\mathrm{p}=0.13$; Table 2).

\section{Diet}

We found a higher percentage of fast-food consumption ( $\geq 2$ times/month) in HEN/LEAD among those infected with COVID-19 with a trend towards statistical significance but not reaching statistical significance $(66.7 \%$ vs $39.6 \%, p=0.07$; Table 1$)$. Higher consumption ( $\geq 2$ times/month) of Mexican tortas (a fast-food sandwich) was also greater among those who were infected versus uninfected $(25.0 \%$ vs $10.9 \%, p=0.15$; Table 1$)$. Beans were consumed more frequently by families with COVID-19 infection compared to those families without COVID-19 infection $(91.7 \%$ vs $70.8 \%, p=0.12$; Table 1$)$.

In the $\mathrm{TAB}$ cohort, there was a trend towards higher consumption of $100 \%$ fruit juice among those infected with COVID-19 versus uninfected although results were not statistically significant $(66.7 \%$ vs $36.8 \%, p=0.14$; Table 2 ). Other dietary intake factors 
Table 2. Family demographics, diet and COVID-19 infection of TAB cohort in the San Francisco Bay Area (Total=200)

\begin{tabular}{|c|c|c|c|c|c|}
\hline & \multicolumn{2}{|c|}{$\begin{array}{c}\text { Infected } \\
\mathrm{N}=7(3.5 \%)\end{array}$} & \multicolumn{2}{|c|}{$\begin{array}{l}\text { Not Infected } \\
\mathbf{N}=193(92.4 \%)\end{array}$} & \multirow[t]{2}{*}{$p$} \\
\hline & $\mathrm{Mean}_{ \pm \mathrm{SD}}$ & Median (IQR) & Mean \pm SD & Median (IQR) & \\
\hline \multicolumn{6}{|l|}{ Demographics } \\
\hline Household size & $5.4 \pm 1.7$ & $5(2)$ & $4.7 \pm 1.7$ & $4(1)$ & 0.17 \\
\hline Number of children & $3.3 \pm 1.3$ & $3(1)$ & $2.4 \pm 1.1$ & $2(1)$ & 0.03 \\
\hline Number sharing bedroom & $2.3 \pm 0.4$ & $2(0.5)$ & $2.5 \pm 1.0$ & $2(1)$ & 0.83 \\
\hline Number sharing bathroom & $4.0 \pm 1.0$ & $4(2)$ & $3.4 \pm 1.7$ & $3(2)$ & 0.14 \\
\hline Number eating together & $2.7 \pm 0.8$ & $2.5(1.5)$ & $3.8 \pm 1.2$ & $4(1)$ & 0.01 \\
\hline Maternal high school diploma (yes vs no), n (\%) & $4(57.1)$ & & $157(81.4)$ & & 0.11 \\
\hline Spanish language (primary), $\mathrm{n}(\%)$ & $3(42.9)$ & & $74(38.5)^{*}$ & & 0.82 \\
\hline \multicolumn{6}{|l|}{ COVID practices } \\
\hline Wearing masks (always), n (\%) & $7(100)$ & & $180(93.3)$ & & 0.48 \\
\hline Using public transportation (never), $\mathrm{n}(\%)$ & $5(71.4)$ & & $172(89.1)$ & & 0.15 \\
\hline Household member working/employed, n (\%) & $7(100)$ & & $145(75.1)$ & & 0.13 \\
\hline \multicolumn{6}{|l|}{ Diet } \\
\hline Fast food ( $\geq 2$ times/month), $\mathrm{n} / \mathrm{N}(\%)$ & $0 / 6(0)$ & & $39 / 193(20.2)$ & & 0.22 \\
\hline Mexican tortas ( $\geq 2$ times/month), n/N (\%) & $0 / 6(0)$ & & 18/193 (9.3) & & 0.43 \\
\hline Sugar sweetened beverages ( $\geq 1$ time/week), $\mathrm{n} / \mathrm{N}(\%)$ & $1 / 6(16.7)$ & & $32 / 193(16.6)$ & & 1.00 \\
\hline Beans/frijoles ( $\geq 1$ time/week), n/N (\%) & $4 / 6(66.7)$ & & 115/193 (59.6) & & 0.73 \\
\hline $100 \%$ Fruit juice ( $\geq 1$ time/week), n/N (\%) & $4 / 6(66.7)$ & & $71 / 193(36.8)$ & & 0.14 \\
\hline \multicolumn{6}{|l|}{ Pollution } \\
\hline $\begin{array}{l}\text { Exposure to secondhand smoke or someone smoking in } \\
\text { household, } n / N(\%)\end{array}$ & $3 / 7(42.9)$ & & $22 / 193(11.4)$ & & 0.01 \\
\hline EnviroScreen 3.0 Pollution burden score & $38.4 \pm 11.8$ & $45.0(25.6)$ & $34.7 \pm 10.1$ & $32.9(15.6)$ & 0.39 \\
\hline EnviroScreen 3.0 Pollution burden percentile & $43.1 \pm 28.5$ & $58.7(61.7)$ & $33.3 \pm 28.8$ & $26.4(39.0)$ & 0.39 \\
\hline
\end{tabular}

* 74/192

including consumption of fast food, sugar sweetened beverages, and $100 \%$ fruit juice were not associated with COVID-19 infection.

\section{Secondhand smoke exposure and environmental pollution}

There was a higher percentage of exposure to secondhand smoke in HEN/LEAD in those families with COVID-19 infection ( $28.6 \%$ vs $18.2 \%$ for those uninfected), although the differences were not statistically significant in bivariate analysis $(p=0.34$; Table 1). We did not find any association between pollution burden score or pollution burden percentile as indicated on the Enviroscreen 3.0 tool related to COVID-19 infection (Table 1).

In $\mathrm{TAB}$, a higher percentage of those with exposure to secondhand smoke had someone in the household with COVID-19 (42.9\% vs $11.4 \%$, $\mathrm{p}=0.01$; Table 2 ). There was no association between pollution burden score or percentile as per Enviroscreen 3.0 and COVID-19 infection (Table 2).

\section{Multivariable findings}

Independent predictors for COVID-19 infection in HEN/LEAD include a higher number of household members in the house ( $\mathrm{OR}=1.58$; 95\% CI: $1.12-2.23$, $\mathrm{p}<0.01$; Table 3). Increased exposure to secondhand smoke was also associated with increased risk for COVID-19 infection adjusting for other factors including number of household members, number of household members eating together and number sharing a bedroom ( $\mathrm{OR}=4.69$; 95\% CI: 1.01-21.85, $\mathrm{p}=0.049$; Table 3). Eating fast-food Mexican torta sandwiches ( $\geq 2$ times/month) approached statistical 
Table 3. Independent household predictors for COVID-19 infection of Latinx families in San Francisco Bay Area: Multivariable logistic regression* $(\mathrm{N}=150$ families; HEN and LEAD cohorts)

\begin{tabular}{llc}
\hline Variable & \multicolumn{1}{c}{ OR (95\% CI $)$} & $p$ \\
\hline Household number & $1.58(1.12-2.23)$ & $<0.01$ \\
Number sharing bedroom & $1.05(0.66-1.68)$ & 0.82 \\
Number eating together at home daily & $1.06(0.73-1.56)$ & 0.75 \\
Exposure to secondhand smoke (any) & $4.69(1.01-21.85)$ & 0.049 \\
Public transportation use (any) & $0.45(0.05-4.06)$ & 0.47 \\
High tortas consumption & $4.54(0.91-22.47)$ & 0.06 \\
$(\geq 2$ times/month) & &
\end{tabular}

*All variables listed are included in the multivariable model.

Table 4. Independent household predictors for COVID-19 infection of Latinx families in San Francisco Bay Area: Multivariable logistic regression* $(\mathrm{N}=199 ; \mathrm{TAB}$ cohort $)$

\begin{tabular}{lll} 
Variable & \multicolumn{1}{c}{ OR (95\% CI) } & $p$ \\
\hline Number of children in house & $3.79(1.51-9.56)$ & $<0.01$ \\
Mother has high school diploma & $0.37(0.05-2.82)$ & 0.34 \\
$\begin{array}{l}\text { Exposure to secondhand smoke (any) } \\
\text { Public transportation use (any) }\end{array}$ & $2.95(0.24-36.11)$ & 0.40 \\
$\begin{array}{l}\text { High fruit juice consumption } \\
\begin{array}{l}\geq 1 \text { time/week) } \\
\text { Number of people eating together at }\end{array}\end{array}$ & $0.10(0.38(0.34-33.97)$ & 0.30 \\
$\begin{array}{l}\text { home daily } \\
\end{array}$ & & $<0.01$ \\
\end{tabular}

*All variables listed are included in the multivariable model.

significance for association with COVID-19 (OR=4.54; 95\% CI: 0.91-22.47, $\mathrm{p}=0.06$; Table 3 ). There was no association in multivariable models assessing high fast food or high frijoles/bean consumption adjusting for other significant variables in relation to COVID-19 infection (results not shown). We also did not find any statistical association between any food/nutrition interaction terms with secondhand smoke exposure and risk for COVID-19 infection when we included interaction terms in models.

Independent predictors for COVID-19 infection in the TAB cohort included having a higher number of household children (OR=3.79; 95\% CI: 1.51-9.56, $\mathrm{p}<0.01$; Table 4) and having more household members present at daily meals, was protective $(\mathrm{OR}=0.10$; 95\% CI: 0.02-0.52, $\mathrm{p}<0.01$; Table 4). There was no association between risk of infection and any use of public transportation, $100 \%$ fruit juice consumption, secondhand smoke exposure, or maternal education, after adjusting for exposure to other variables.

\section{DISCUSSION}

\section{Household crowding and sheltering in place}

Similar to previous studies, we found that larger households are associated with COVID-19 infection in both our HEN/LEAD and TAB Latinx cohorts, as indicated by total household members and number of children in the household. Since the start of the pandemic, most COVID-19 transmission occurs in the context of close interpersonal interactions in the home ${ }^{27}$. In counties where there are high levels of overcrowding, there is a strong association between COVID-19 infection and overcrowding in the home ${ }^{28}$. Overcrowding occurs when people in a home surpass the home's capacity to supply privacy, shelter, and space, as per the WHO definition ${ }^{29}$. Implications of overcrowding include increased likelihood of infection and a greater prevalence of respiratory ailments ${ }^{30}$. The most vulnerable populations for crowding and housing difficulties include those with mental illness, chronic health conditions, history of trauma, immigrants, and ethnic/racial minorities ${ }^{31-34}$. Similar to US-based studies, Black, Asian and ethnic minorities in the United Kingdom report increased risk for COVID-19 associated with household crowding ${ }^{35}$. Investment in adequate housing in the San Francisco Bay Area could reduce risk for infection in high-risk populations including parts of the Latinx community, that have a higher rate of household crowding.

In the TAB cohort, we also found that having more members at home eating meals together was protective against infection. As we did not directly ask questions about working outside of the home, it is likely that eating meals together was a proxy variable in our cohort for being able to shelter in place and work inside the home. Among Latinx families in the San Francisco Bay Area, previous studies have found a strong association between being an essential worker or working outside the home and risk of COVID-19 infection ${ }^{36}$. Since the beginning of the pandemic in early 2020, recommendations have been made to protect essential workers including use of masks/ face coverings, hand hygiene, widespread vaccination coverage and appropriate ventilation of indoor spaces ${ }^{37}$. 


\section{Public health measures and interventions to reduce household crowding}

Public health measures to reduce overcrowding have traditionally been at the individual level ${ }^{38}$. Interventions for COVID-19 should minimize the number of contacts people with COVID-19 infection have, particularly household contacts. In China, the government provides COVID-19 infected individuals with space to quarantine outside the home and access to free meals, internet, and telephone, thus limiting COVID-19 household transmission ${ }^{39}$. In California, hotels have been used as temporary housing locations for high-risk populations, including homeless and healthcare workers at risk of COVID-19 infection but these interventions have not been extended to the general population ${ }^{40}$.

Enforcing housing guidelines and codes may be a mechanism to address overcrowding and ensure appropriate ventilation in units; however, there must be a safety net to help families should they need to be relocated due to housing code violations ${ }^{41}$.

\section{Secondhand smoke and environmental pollutants}

Secondhand smoke and environment exposures such as pollution increase risk for respiratory illness ${ }^{42-44}$. Secondhand smoke consists of more than 7000 different chemicals from smoke exhaled by a smoker and additional smoke from the cigarette. In the US, approximately 40000 deaths per year are attributed to secondhand smoke in non-smokers ${ }^{42}$. We found increased risk associated with exposure to secondhand smoke in our combined HEN/LEAD cohort but not in the TAB cohort, once other variables had been adjusted for including household size. It is possible that we were not able to confirm any association between secondhand smoke exposure and COVID in $\mathrm{TAB}$ due to inadequate power; there were a smaller number of COVID-19 infections in the TAB cohort (3.5\% vs $7.6 \%)$. Future population-based studies are needed with larger sample sizes and greater number of infections to confirm our findings. Similarly, there was no association between COVID-19 infection and environmental pollution exposures as indicated by census track data; it is possible at the level of household census track, we did not have sufficiently granular data to assess differences between neighborhood areas.

Secondhand smoke may facilitate transmission of COVID-19 as the virus attaches to particles expelled by smokers and can travel longer distances ${ }^{45}$. Viral particles can travel up to six times farther than if the virus was simply in the air in the absence of smoke $^{45}$. Furthermore, smokers tend to exhale more forcefully, and COVID-19 infected smokers could have more particles pushed from their lungs to travel greater distances ${ }^{46}$. Previous studies suggest that Latinx households residing in multi-unit housing are exposed to secondhand smoke at very high levels ${ }^{47}$ with children being the most vulnerable ${ }^{43}$. With pandemic stay-at-home orders in the greater Bay Area, families likely had limited options in a confined space particularly if a household member smokes or there is smoking within a multi-unit residence.

\section{Public health measures to address secondhand smoke}

Families living in densely packed urban areas or in multi-housing units that do not restrict smoking can be impacted by secondhand smoke exposure ${ }^{48}$. In California, more than 60 cities and counties have $100 \%$ smoke-free multi-housing units where smoking is prohibited in privately-owned as well as publicly-owned residences. Bay Area municipalities with 100\% smoke-free laws include Berkeley, Daly City, South San Francisco, Pacifica, and Palo Alto ${ }^{49}$. About two dozen municipalities in California have laws partially restricting smoking in multi-housing units. Municipalities with partial smoking restrictions are less stringent than the $100 \%$ smoke-free laws as smoking is restricted in some private units of multiunit housing, yet do not mandate multi-unit homes to be $100 \%$ smoke-free ${ }^{49}$. Municipalities in the Bay Area with partial smoking laws include Fremont, Marin County, and Pinole ${ }^{49}$.

Secondhand smoking is a concern in residential housing in San Francisco, where many of our participants live ${ }^{42}$. In 2010, Health Code Article $19 \mathrm{~F}$ passed in San Francisco preventing smoking in shared areas in multi-unit buildings but allows smoking in individual units and outdoors on private patios or balconies and on street curbs near multiunit complexes ${ }^{42}$. As such secondhand smoke can easily flow between units through ventilation systems, windows and doors. With the growing usage of e-cigarettes, San Francisco has begun prohibiting vaping in any location where there is no use of traditional cigarettes with the law SF Health Code 
Article 19N (2014), as secondhand vapor also has respiratory health impacts ${ }^{50}$. However, secondhand vapor can similarly flow between units in multi-unit residential complexes.

In December 2020, San Francisco chose not to revise Health Code Article 19F and as such there is no legislation in San Francisco to prohibit smoking inside private dwellings in complexes with three or more units ${ }^{51}$. Although Senate Bill-322 will continue to allow landlords to place smoking bans, residents in many multi-use units will continue to face exposure to secondhand smoke and potential increased risk of COVID-19 exposure ${ }^{51}$. Similarly, other East Bay and Peninsula cities where our participants reside including Oakland, San Jose, and Vallejo, do not have any legislation restricting smoking in multi-housing units.

In the context of COVID-19 shelter-in-place mandates, families spent an increased amount of time at home, with a greater risk for secondhand smoke exposure in the household if neighbors or other household members smoke. In the context of COVID-19, there has been a greater urgency to reform smoking and housing laws to protect residents in multi-unit dwellings.

\section{Nutrition and risk for COVID-19}

We did not find any statistically significant dietary risk factors for COVID-19 after adjusting for crowding indices and exposure to secondhand smoke in multivariable models, although the association between increased consumption of Mexican fastfood torta sandwiches trended towards statistical significance in the HEN/LEAD cohort. In bivariate analyses, increased consumption of Mexican tortas, fast food and 100\% fruit juice were associated with increased risk for infection. Additionally, families consuming more beans/frijoles trended towards having COVID-19 infection compared to those eating beans with less frequency, possibly a marker of low socioeconomic status. Beans are more likely to be incorporated in the diet of individuals who are less socioeconomically privileged than in the diets of people with greater resources ${ }^{52}$. Having beans in the home tends to provide a sense of food security ${ }^{53}$. We found no statistically significant relationship between fast food, Mexican tortas and 100\% fruit juice consumption and COVID-19 infection, but the families in HEN/LEAD who ate fast food including Mexican tortas more than twice a month had more COVID-19 infection relative to individuals who ate fast food less frequently. Fast food and 100\% fruit juice consumption are associated with increased risk of being overweight and obese, and metabolic diseases due to the high amount of sugar and fats in these foods ${ }^{54}$. As the novel coronavirus pandemic resulted in changing eating behaviors and decreasing quality of diets, in part due to food insecurity, there may be greater risk for infection in families with higher consumption of fast foods, sugar sweetened beverages or other food stuffs associated with obesity and metabolic disease ${ }^{17}$.

Alternatively, in previous studies, community exposure activities, including restaurant or coffee shop dining, increase the risk for COVID-19 infection ${ }^{55}$. Adults testing positive for COVID-19 infection were twice as likely to have dined at a restaurant 14 days before becoming ill compared to those testing negative ${ }^{55}$. Consumption of fast food, such as Mexican tortas or American style fast food, may be synonymous with increased exposure of individuals outside the household or may suggest risk associated with eating at restaurants. Similarly, the number of individuals eating at home was protective against infection in our TAB cohort.

We did not find any statistically significant interactions between secondhand smoke exposure, nutritional health and COVID-19 outcomes. In contrast, previous studies that have found interaction between secondhand smoke exposure, nutritional intake and health outcomes, it is possible that our study was underpowered ${ }^{21,56}$. Our sample size was small for this study as were total number of COVID-19 infections and future studies should be conducted with larger population groups.

\section{Strengths and limitations}

Limitations of this study include small sample size and number of COVID-19 infections. We also did not directly test participants for COVD-19 but relied on self-reported results including recall of COVID-19 related symptoms. Our assessment of secondhand smoke exposure was collected annually and not directly before the start of the COVID-19 pandemic in some cases and environmental pollutant exposure was based on census track location, not at the household 
or individual level. Lastly, we did not directly assess other forms of tobacco exposure including the effects of e-cigarettes on COVID-19 infections. Future COVID-19 policy measures in the San Francisco Bay Area could include better implementation of housing guidelines to ensure adequate space and ventilation as well as greater inclusion of all individuals for benefits related to healthy living, like hotel housing following COVID-19 infection. Additionally, policy on secondhand smoke exposure should restrict any exposures in multi-unit dwellings by banning any smoking in multi-unit dwellings in San Francisco and other Bay Area cities that do not have existing smoking bans.

\section{CONCLUSIONS}

Crowding as indicated by household size increases risk for COVID-19 infection in Latinx families, as did exposure to secondhand smoke. Public policy and health interventions need to ensure that multi-unit residential complexes prevent exposure to secondhand smoke, that individuals eat in the home environment, and that large households are able to safely separate individuals exposed to COVID-19.

\section{REFERENCES}

1. Centers for Disease Control and Prevention. Vaccinations $>$ Variants. Centers for Disease Control and Prevention; 2021. Accessed June 4, 2021. https://www.cdc.gov/ coronavirus/2019-ncov/covid-data/covidview/index.html

2. Tai DBG, Shah A, Doubeni CA, Sia IG, Wieland ML. The Disproportionate Impact of COVID-19 on Racial and Ethnic Minorities in the United States. Clin Infect Dis. 2021;72(4):703-706. doi:10.1093/cid/ciaa815

3. Centers for Disease Control and Prevention. Demographic Trends of COVID cases and deaths in the US Reported to CDC. Centers for Disease Control and Prevention; 2021. Accessed June 4, 2021. https://covid.cdc.gov/covid-datatracker/\#demographics

4. American Academy of Pediatrics. Children and COVID-19: State-Level Data Report. Accessed June 2, 2021. https:// services.aap.org/en/pages/2019-novel-coronaviruscovid-19-infections/children-and-covid-19-state-leveldata-report/

5. California Department of Public Health. COVID-19 Race and Ethnicity Data. California Department of Public Health; 2021. Accessed June 3, 2021. https://www.cdph. ca.gov/Programs/CID/DCDC/Pages/COVID-19/RaceEthnicity.aspx

6. Van Dyke ME, Mendoza MC, Li W, et al. Racial and Ethnic Disparities in COVID-19 Incidence by Age,
Sex, and Period Among Persons Aged <25 Years 16 U.S. Jurisdictions, January 1-December 31, 2020. MMWR Morb Mortal Wkly Rep. 2021;70:382-388. doi:10.15585/mmwr.mm7011e1

7. Tran J. Reducing Health Disparities Among Low Socioeconomic Status Hispanics in the United States. Accessed October 3, 2021. https:// digitalcommons.providence.edu/cgi/viewcontent. cgi? article $=1049 \&$ context $=$ sbg

8. US Bureau of Labor Statistics. Job Flexibilities and Work Schedules Summary. September 24, 2019. Accessed November 30, 2020. https://www.bls.gov/news.release/ flex2.nr0.htm

9. Khazanchi R, Beiter ER Gondi S, Beckman AL, Bilinski A, Ganguli I. County-level association of social vulnerablity with COVID-19 cases and deaths in the USA. J Gen Intern Med. 2020;35(9)2784-2787. doi:10.1007/s11606-020-05882-3

10. California Senate Office of Research. A Statistical Picture of Latinos in California 2017 Update. California Senate Office of Research; 2017. Accessed October 4, 2021. https://latinocaucus.legislature.ca.gov/sites/latinocaucus. legislature.ca.gov/files/forms/Statistical\%20Picture $\% 20$ of $\% 20$ Latinos $\% 20 \mathrm{in} \% 20$ California $\% 20-\% 202017 \% 20$ Update.pdf

11. Costello P. Why air pollution is linked to severe cases of COVID-19. SCOPE. Published July 17, 2020. Accessed November 22, 2020. https://scopeblog.stanford. edu/2020/07/17/why-air-pollution-is-linked-to-severecases-of-covid-19/

12. Fell AKM, Svendsen MV, Kim JL, et al. Exposure to second-hand tobacco smoke and respiratory symptoms in non-smoking adults: cross-sectional data from the general population of Telemark, Norway. BMC Public Health. 2018;18(1):843. doi:10.1186/s12889-018-5771-4

13. Roth S. Boiling Point: These maps show how air pollution and COVID-19 can be a deadly mix. Los Angeles Times. October 8, 2020. Accessed November 22, 2020. https:// www.latimes.com/environment/newsletter/2020-10-08/ boiling-point-air-pollution-and-covid-19-can-be-adeadly-mix-boiling-point

14. Harvard T.H. Chan School of Public Health. Coronavirus and Air Pollution. Accessed November 22, 2020. https:// www.hsph.harvard.edu/c-change/subtopics/coronavirusand-pollution/

15. American Lung Association. Disparities in the Impact of Air Pollution. Updated April 20, 2020. Accessed November 24, 2020. https://www.lung.org/clean-air/ outdoors/who-is-at-risk/disparities

16. Ghosh A, Arora B, Gupta R, Anoop S, Misra A. Effects of nationwide lockdown during COVID-19 epidemic on lifestyle and other medical issues of patients with type 2 diabetes in north India. Diabetes Metab Syndr. 2020;14(5):917-920. doi:10.1016/j.dsx.2020.05.044

17. Khubchandani J, Kandiah J, Saiki D. The COVID-19 
pandemic, stress, and eating practices in the United States. Eur J Investig Health Psychol Educ. 2020;10(4):950-956. doi:10.3390/ejihpe10040067

18. Rhodes J, Dunstan F, Laird E, Subramanian S, Kenny RA. COVID-19 mortality increases with northerly latitude after adjustment for age suggesting a link with ultraviolet and vitamin D. BMJ Nutr Prev Health. 2020;3(1):118120. doi:10.1136/bmjnph-2020-000110

19. Bae M, Kim H. Mini-Review on the Roles of Vitamin C, Vitamin D, and Selenium in the Immune System against COVID-19. Molecules. 2020;25(22):5346. doi:10.3390/molecules25225346

20. Butler MJ, Barrientos RM. The impact of nutrition on COVID-19 susceptibility and long-term consequences. Brain Behav Immun. 2020;87:53-54. doi:10.1016/j.bbi.2020.04.040

21. Whyand T, Hurst JR, Beckles M, Caplin ME. Pollution and respiratory disease: can diet or supplements help? A review. Respir Res. 2018;19(1):79. doi:10.1186/s12931-018-0785-0

22. Kjaer TW, Faurholt-Jepsen D, Medrano R, et al. Higher Birthweight and Maternal Pre-pregnancy BMI Persist with Obesity Association at Age 9 in High Risk Latino Children. J Immigr Minor Health. 2019;21(1):89-97. doi:10.1007/s10903-018-0702-0

23. Wojcicki JM, Holbrook K, Lustig RH, et al. Chronic maternal depression is associated with reduced weight gain in latino infants from birth to 2 years of age. PLoS One. 2011;6(2):e16737. doi:10.1371/journal.pone.0016737

24. Ville AP, Heyman MB, Medrano R, Wojcicki JM. Early Antibiotic Exposure and Risk of Childhood Obesity in Latinos. Child Obes. 2017;13(3):231-235. doi:10.1089/chi.2016.0235

25. Wojcicki JM, Medrano R, Lin J, Epel E. Increased Cellular Aging by 3 Years of Age in Latino, Preschool Children Who Consume More Sugar-Sweetened Beverages: A Pilot Study. Child Obes. 2018;14(3):149-157. doi:10.1089/chi.2017.0159

26. CalEnviroScreen 3.0. Version 3.0. California Office of Environmental Health Hazard Assessment; 2018. Accessed December 13, 2020. https://oehha.ca.gov/ calenviroscreen/report/calenviroscreen-30

27. Rader B, Scarpino SV, Nande A, et al. Crowding and the shape of COVID-19 epidemics. Nat Med. 2020;26(12):1829-1834. doi:10.1038/s41591-020-1104-0

28. Richwine J, Caramota SA, Zeigler K. Househld overcrowding facilitates the spread of COVID-19. Center for Immigration Studies; 2020. Accessed January 13, 2021. https://cis.org/Richwine/HouseholdOvercrowding-Facilitates-Spread-Covid19

29. Shannon H, Allen C, Clarke M, et al. Web Annex A: Report of the Systematic Review on the Effect of Household Crowding on Health. In: WHO Housing and Health Guidelines. World Health Organization; 2018. Accessed January 30, 2021. http://apps.who.int/iris/bitstream/ handle/10665/275838/WHO-CED-PHE-18.02-eng.pdf
30. Cardoso MRA, Cousens SN, de Góes Siqueira LF, Alves FM, D'Angelo L. Crowding: risk factor or protective factor for lower respiratory disease in young children? BMC Public Health. 2004;4:19. doi:10.1186/1471-2458-4-19

31. Anderson HS, Turner LM, Soholt S. The special importance of housing policy for ethnic minorities: evidence from comparison of four Nordic countries. International Journal of Housing Policy. 2013;13(1):2044. doi:10.1080/14616718.2013.764659

32. Braubach M. Key challenges of housing and health from WHO perspective. Int J Public Health. 2011;56(6):579580. doi:10.1007/s00038-011-0296-y

33. Dohler E, Bailey P, Rice D, Katch H. Supportive housing helps vulnerable people live and thrive in the community. Center on Budget and Policy Priorities; 2016. Accessed January 13, 2021. https://www.cbpp.org/sites/default/ files/atoms/files/5-31-16hous.pdf

34. Jones A. Black and minority ethnic communities' experience of overcrowding. Better Housing Briefing 16. Race Equality Foundation; 2010. Accessed January 13, 2021. https://raceequalityfoundation.org.uk/wp-content/ uploads/2018/02/housing-brief16.pdf

35. Soltan M, Crowley LE, Melville CR, et al. To what extent are social determinants of health, including household overcrowding, air pollution and housing quality deprivation, modulators of presentation, ITU admission and outcomes among patients with SARS-COV-2 infection in an urban catchment area in Birmingham, United Kingdom? Research Square Platform LLC; 2020. doi:10.21203/rs.3.rs-35617/v1

36. Chamie G, Marquez C, Crawford E, et al. SARS-CoV-2 Community Transmission disproportionately affects Latinx population during Shelter-in-Place in San Francisco. Clin Infect Dis. 2020. doi:10.1093/cid/ciaa1234

37. Honein MA, Christie A, Rose DA, et al. Summary of Guidance for Public Health Strategies to Address High Levels of Community Transmission of SARSCoV-2 and Related Deaths, December 2020. MMWR Morb Mortal Wkly Rep. 2020;69(49):1860-1867. doi:10.15585/mmwr.mm6949e2

38. Shaw M. Housing and public health. Annu Rev Public Health. 2004;25:397-418. doi:10.1146/annurev. publhealth.25.101802.123036

39. Lai S, Ruktanonchai NW, Zhou L, et al. Effect of nonpharmaceutical interventions to contain COVID-19 in China. Nature. 2020;585(7825):410-413. doi:10.1038/s41586-020-2293-x

40. Official California State Government Website. Help for people without housing. Accessed January 3, 2021. https://covid19.ca.gov/housing-andhomelessness/\#people-without-housing

41. Krieger J, Higgins DL. Housing and health: time again for public health action. Am J Public Health. 2002;92(5):758768. doi:10.2105/ajph.92.5.758

42. San Francisco Tobacco-Free Project. Smoke Free 
Housing. Accessed January 12, 2021. https:// sanfranciscotobaccofreeproject.org/housing

43. Zeng S, Noguchi H, Shimokawa S. Partial Smoking Ban and Secondhand Smoke Exposure in Japan. Int J Environ Res Public Health. 2019;16(15):2804. doi:10.3390/ijerph16152804

44. Centers for Disease Control and Prevention. Smoking and Overall Health. Accessed December 13, 2020. https://www.cdc.gov/tobacco/data_statistics/sgr/50thanniversary/pdfs/fs_smoking_overall_health_508.pdf

45. Curley B. Can Secondhand Smoke Transmit the Novel Coronavirus? Healthline. August 17, 2020. Accessed January 14, 2021. https://www.healthline.com/healthnews/can-secondhand-smoke-transmit-the-novelcoronavirus

46. Ries J. People Without Symptoms Carry Just as Much of the Coronavirus as Symptomatic People. Healthline. August 10, 2020. Accessed January 13, 2021. https:// healthline.com/health-news/people-without-symptomscarry-just-as-much-covid-19-as-symptomatic-people

47. Baezconde-Garbanati LA, Weich-Reushé K, Espinoza L, et al. Secondhand smoke exposure among Hispanics/ Latinos living in multiunit housing: exploring barriers to new policies. Am J Health Promot. 2011;25(5 Suppl):S82-S90. doi:10.4278/ajhp.100628-QUAL-219

48. Pickett MS, Schober SE, Brody DJ, Curtin LR, Giovino GA. Smoke-free laws and secondhand smoke exposure in US non-smoking adults, 1999-2002. Tob Control. 2006;15(4):302-307. doi:10.1136/tc.2005.015073

49. American Nonsmokers' Rights Association. U.S. Laws for $100 \%$ Smokefree Multi-Unit Housing. American Nonsmokers' Rights Association; 2021. Accessed June 7, 2021. https://no-smoke.org/wp-content/uploads/pdf/ smokefreemuh.pdf

50. San Francisco Tobacco-Free. San Francisco Tobacco Control Laws. Updated March 2019. Accessed June 7, 2021. https://sanfranciscotobaccofreeproject.org/sftobacco-control-laws/

51. Moench M. S.F. reverses course on tobacco smoking ban inside apartment buildings, seeks more review. December 8, 2020. Accessed January 11, 2021. San Francisco Chronicle. https://www.sfchronicle.com/bayarea/article/ S-F-reverses-course-on-tobacco-smoking-ban-15785819. php

52. Medina LPB, Barros MBA, Barros Filho AA. Social inequalities in the consumption of beans and other legumes: a study with adults from Brazil. Eur J Public Health. 2020;30(Supplement_5).doi:10.1093/eurpub/ckaa166.325

53. Khor LY, Zeller M. Storing a staple crop for own consumption: Linkages to food security. International Association of Agricultural Economists 2018 Conference. 2018. doi:10.22004/AG.ECON.277244

54. Janssen HG, Davies IG, Richardson LD, Stevenson L. Determinants of takeaway and fast food consumption: a narrative review. Nutr Res Rev. 2018;31(1):16-34.
doi:10.1017/S0954422417000178

55. Fisher KA, Tenforde MW, Feldstein LR, et al. Community and Close Contact Exposures Associated with COVID-19 Among Symptomatic Adults $\geq 18$ Years in 11 Outpatient Health Care Facilities - United States, July 2020. MMWR Morb Mortal Wkly Rep. 2020;69(36):1258-1264. doi:10.15585/mmwr.mm6936a5

56. Jung CY, Park H, Kim DW, et al. Association between Body Mass Index and Risk of COVID-19: A Nationwide Case-Control Study in South Korea. Clin Infect Dis. 2020:ciaa1257. doi:10.1093/cid/ciaa1257

\section{CONFLICTS OF INTEREST}

The authors have each completed and submitted an ICMJE form for disclosure of potential conflicts of interest. The authors declare that they have no competing interests, financial or otherwise, related to the current work. J.M. Wojcicki reports funding in support of this article made to her institution (UCSF) since the initial planning of the work from Covid-19 catalyst at the Center of Emerging and Neglected Diseases.

\section{FUNDING}

This project was supported by the generosity of Eric and Wendy Schmidt by recommendation of the Schmidt Futures program, through Covid Catalyst at the Center of Emerging and Neglected Diseases. The project was also supported by Marc and Lynne Benioff.

\section{ETHICAL APPROVAL AND INFORMED CONSENT}

The Committee on Human Research (CHR) of the UCSF Institutional Review Board approved all aspects of the study. Participants gave verbal informed consent for the 15-minute interview. The participants in the present study were part of three, existing longitudinal cohort studies approved on 4/10/2020 (No. 11-06136), 4/15/2020 (No. 11-06334) and 5/1/2020 (No.16-18535).

\section{DATA AVAILABILITY}

The data supporting this research are available from the authors on reasonable request.

\section{PROVENANCE AND PEER REVIEW}

Not commissioned; externally peer reviewed. 